CLINICAL STUDY

\title{
Gamma knife radiosurgery: a safe and effective salvage treatment for pituitary tumours not controlled despite conventional radiotherapy
}

\author{
F M Swords ${ }^{1}$, J P Monson, G M Besser, S L Chew, W M Drake, A B Grossman and P N Plowman \\ Department of Oncology, Barts and the London NHS Trust, West Smithfield, London EC1A 7BE, UK and ${ }^{1}$ Norfolk and Norwich University Hospital NHS \\ Foundation Trust, Norwich, UK
}

(Correspondence should be addressed to P N Plowman; Email: nick.plowman@bartsandthelondon.nhs.uk)

\begin{abstract}
Objective: We report the use of 'gamma knife' (GK) radiosurgery in 25 patients with pituitary adenomas not cured despite conventional therapy, including external beam radiotherapy.

Patients and methods: All patients had previously received conventional radiotherapy for a mean of 11.8 years prior to receiving GK; 23 out of 25 had also undergone pituitary surgery on at least one occasion. Seventeen had hyperfunctioning adenomas that still required medical therapy without an adequate biochemical control - ten somatotroph adenomas, six corticotroph adenomas and one prolactinoma, while eight patients had non-functioning pituitary adenomas (NFPAs).

Results: Following GK, mean GH fell by $49 \%$ at 1 year in patients with somatotroph tumours. Serum IGF 1 fell by $32 \%$ at 1 year and by $38 \%$ at 2 years. To date, $80 \%$ of the patients with acromegaly have achieved normalisation of IGF1, and 30\% have also achieved a mean GH level of $<1.8 \mathrm{ng} / \mathrm{ml}$ correlating with normalised mortality. A total of $75 \%$ NFPAs showed disease stabilisation or shrinkage post GK. The patient with a prolactinoma showed a dramatic response: $75 \%$ reduction in prolactin at 2 years, with a marked shrinkage on magnetic resonance imaging. The results in corticotroph adenomas were variable. Prior to GK, $72 \%$ of the patients were panhypopituitary, and $42 \%$ of the remainder have developed new anterior pituitary hormone deficiencies to date. No other adverse events have been detected at a mean follow-up of 36.4 months.

Conclusions: These data indicate that GK is a safe and effective adjunctive treatment for patients with NFPAs and acromegaly not satisfactorily controlled with surgery and radiotherapy.
\end{abstract}

European Journal of Endocrinology 161 819-828

\section{Introduction}

Neurosurgical treatments for pituitary tumours have rapidly advanced with the advent of magnetic resonance imaging (MRI), stereotactic CT mapping and advances in transsphenoidal surgery techniques. However, up to $60 \%$ of the patients with functioning pituitary tumours continue to show biochemical disease activity after surgery $(1,2)$, and non-functioning pituitary adenomas (NFPAs) continue to display high rates of recurrence even following radical surgery (3). Conventional radiotherapy (CRT) for pituitary tumours has therefore long had an established role, and results in a predictable decline in hormonal activity and tumour stabilisation in the majority of cases $(3,4)$. However, despite surgery and radiotherapy, $\sim 10 \%$ of the pituitary tumours will still not be 'cured' in terms of either rendering hormone levels safe or preventing tumour recurrence, and the efficacy of CRT may take many years to fully occur $(3,4)$.

Long-term medical treatments or further surgery is thus frequently used following non-curative radiotherapy for hyperfunctioning pituitary tumours. Somatostatin analogues can be particularly effective at controlling both size and biochemical activity of somatotroph adenomas. However, they are expensive, require parenteral administration and are incompletely effective in $\sim 40 \%$ of the patients. The $\mathrm{GH}$ receptor antagonist pegvisomant appears to be highly effective in controlling serum insulin-like growth factor 1 (IGF1) (5), but it is also expensive, needs to be given parenterally, is not universally available and does not control residual tumour growth.

Dopamine agonists are highly effective at controlling both the size and hypersecretion of prolactinomas, but can be associated with adverse events, e.g. psychiatric disturbance and fibrotic reactions. 
Currently used medical treatments can partly control cortisol excess, but they are ineffective at controlling corticotroph hypersecretion and size.

Unfortunately, no medical treatments are reliably effective for NFPAs. Repeat application of high-dose CRT has been attempted. Historically, this was associated with unacceptably high adverse events, particularly optic neuropathy, and although with increased availability of highly conformal fractionated radiotherapy, this is advocated by selected units and remains under evaluation $(6,7)$. Repeated surgery thus remains the only widely available option for such patients demonstrating further growth despite surgery and radiotherapy.

Hence, there exist a cohort of patients in whom a clinical need for another definitive treatment remains.

There is now extensive experience of 'radiosurgery', a single-dose multiple-port-focussed radiotherapy for pituitary tumours, as an alternative to CRT, and there are multiple reports of repeat applications of such a radiosurgery. Proponents of radiosurgery generally assume a lower incidence of significant side effects, and in some cases there is an accelerated fall in hormone levels when compared to CRT (8-11), although these data are inconsistent.

Our unit in London has extensive experience in pituitary radiotherapy, and has previously reported the use of both CRT and linear accelerator-based stereotactic radiosurgery to pituitary tumours (12-16). Here, we report the use of 'gamma knife' (GK) radiosurgery to 25 cases of pituitary adenomas not adequately controlled despite conventional treatments including radiotherapy.

\section{Patients and methods}

\section{Patients}

We present data on 25 consecutive patients with ongoing pituitary disease despite previous conventional treatments. All patients with NFPAs had evidence of tumour regrowth on serial scanning. All patients with functioning pituitary tumours had an ongoing hormone excess not controlled by or intolerant of medical therapy. All patients had undergone CRT, and 23 out of 25 had also undergone pituitary surgery on at least one occasion: eight on two occasions, and one on three occasions. The clinical details of patients are summarised in Tables 1 and 2.

Tumours were only considered for GK if they were anatomically defined on MRI scanning, and were more than $3 \mathrm{~mm}$ from the optic chiasm in order to minimise chiasmal radiation exposure as discussed below. No upper size limit was defined.

\section{Acromegaly}

We present data on ten patients with somatotroph adenomas. All had previously undergone CRT though none had achieved disease remission. The full data for disease activity at the time of diagnosis and at CRT administration are not available. Published reports estimate a $50 \%$ fall in $\mathrm{GH}$ within the first 2 years of CRT (14), and this cohort had received a modal dose of $45 \mathrm{~Gy}$ at a mean interval of 13.3 years (range 1.5-43 years) before GK delivery. Patients were thus generally deemed to be within the plateau phase of CRT before GK was considered. In the four patients in whom full data

Table 1 Clinical details of patients with somatotroph adenomas.

\begin{tabular}{|c|c|c|c|c|c|c|c|c|c|c|}
\hline Patient & Age & Gender & Surgery & $\begin{array}{l}\text { CRT } \\
\text { (Gy) }\end{array}$ & $\begin{array}{c}\text { GK dose } \\
\text { (Gy) }\end{array}$ & $\begin{array}{c}\text { Diagnosis } \\
\text { GK (y) }\end{array}$ & $\begin{array}{c}\text { CRT GK } \\
\text { (y) }\end{array}$ & $\begin{array}{l}\text { Follow-up } \\
\qquad(\mathrm{m})\end{array}$ & $\begin{array}{l}\text { Pituitary } \\
\text { function }\end{array}$ & Treatment \\
\hline 1 & 52 & M & TSS $\times 2$ & 45 & 15 & 16 & 16 & 36 & Panhypopituitary & Peg \\
\hline 2 & 73 & $\mathrm{~F}$ & None & Yttrium & 10 & 43 & 43 & 36 & Panhypopituitary & $\mathrm{Nil}$ \\
\hline 3 & 66 & M & TSS $\times 1$ & 45 & 15 & 18 & 17 & 33 & $\begin{array}{l}\text { Partial loss post } \\
\text { GK }\end{array}$ & Nil \\
\hline 4 & 58 & $\mathrm{M}$ & TSS X1 & 45 & 17.5 & 16 & 15 & 66 & Panhypopituitary & SA \\
\hline 5 & 50 & $M$ & None & 45 & 15 & 14 & 14 & 9 & $\begin{array}{l}\text { Partial } \\
\text { hypopituitary }\end{array}$ & Nil \\
\hline 6 & 57 & M & TSS $\times 1$ & 45 & 10 & 16 & 7 & 55 & $\begin{array}{l}\text { Partial loss post } \\
\text { GK }\end{array}$ & $S A^{a}$ \\
\hline 7 & 34 & $\mathrm{~F}$ & $\begin{array}{l}\text { TSS X1, } \\
\text { TFS X1 }\end{array}$ & 45 & 10 & 4 & 3 & 78 & Panhypopituitary & Nil \\
\hline 8 & 53 & M & TSS $\times 1$ & 45 & 16 & 11 & 10 & 12 & Panhypopituitary & $S A^{b}$ \\
\hline 9 & 37 & M & TFS $\times 1$ & 40 & 10 & 7 & 6 & 54 & Normal & $\mathrm{Peg}+\mathrm{SA}$ \\
\hline 10 & 30 & $\mathrm{~F}$ & TSS & 45 & 10 & 1.5 & 1.5 & 6 & Normal & Peg \\
\hline
\end{tabular}

TSS, transsphenoidal surgery; TFS, transfrontal surgery; CRT, conventional radiotherapy; GK, gamma knife radiosurgery; y, years; m, months; Peg, pegvisomant; SA, somatostatin analogue. The column headed pituitary function indicates the level of anterior pituitary function at the time of GK: panhypopituitary patients were therefore requiring full hormone replacement therapy prior to receiving gamma knife. Where this is indicated as normal, the patients continue to have normal pituitary function on dynamic testing at their latest follow-up. One had partial pituitary deficiency at the time of gamma knife which remains unchanged, and in two patients, partial loss of anterior pituitary function has been detected since gamma knife treatment as indicated. Where indicated, patients were taking medical treatments throughout the treatment and follow-up periods. All the assessments were made on the same medical therapy.

${ }^{a} \mathrm{~A}$ patient on somatostatin analogue therapy at the time of GK, in whom treatment was stopped for all pre- and post-GK assessments.

${ }^{\mathrm{b}} \mathrm{A}$ patient on somatostatin analogue therapy at the time of GK, and for his assessments to 12 months, but in whom excellent control was achieved and medical treatment was subsequently stopped. 


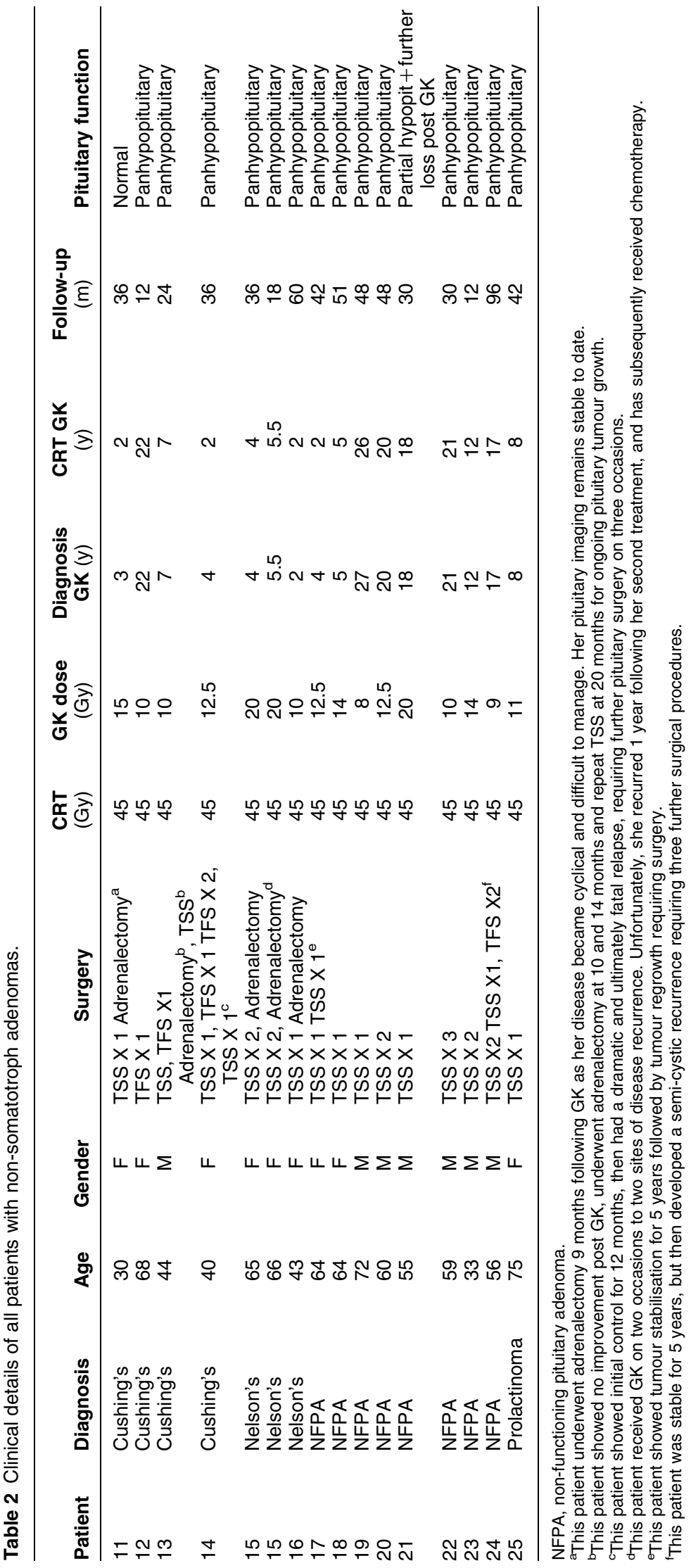


are available, mean $\mathrm{GH}$ had fallen by $62 \%$ over a mean of 17 years following CRT and prior to receiving GK: from 38 to $13 \mathrm{mIU} / \mathrm{l}$.

Two patients had not undergone previous standard surgery: one had received an Yttrium implant at diagnosis 43 years ago, and the other had multiple medical problems and so received primary CRT rather than surgery.

Patients were considered for GK only if they were not satisfactorily controlled on medical therapy. Satisfactory control was deemed to be a mean GH below $1.8 \mathrm{ng} / \mathrm{ml}$ and a normal age- and gender-related serum IGF1 and well-controlled symptoms. This patient group was considered to have an ongoing residual disease rather than a recurrent disease, as none had previously achieved remission without unacceptably high doses of medical treatments.

Where possible, patients were taken off the treatment both for the administration of GK and for all the assessments as indicated in Table 1 and Fig. 1. However, $60 \%$ were on medical treatments at the time of
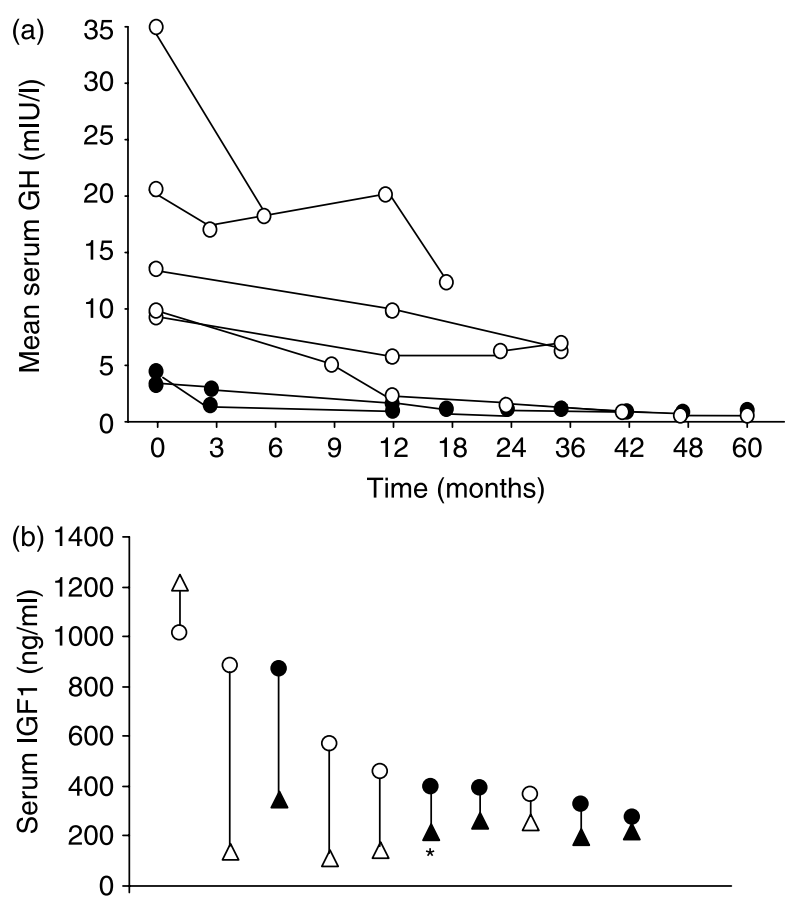

Figure 1 (a) Graph illustrating the decline in mean value of a fivepoint day curve of serum GH following gamma knife radiotherapy in the seven patients not receiving pegvisomant therapy. (b) Serum IGF1 levels for each patient before and following gamma knife radiotherapy. Circles indicate values pre-GK, with triangles indicating the latest IGF1 value. Open symbols represent assessments made off all the medical treatments, filled symbols reflect assessments taken on medical therapy - as indicated in Table 1 and described in methods. *Indicates the patient on somatostatin analogue therapy at the time of GK, and for his assessments, but in whom excellent control was achieved and medical treatment was subsequently stopped.
GK: three were on long-acting somatostatin analogues, two were on pegvisomant, and one was on both treatments.

\section{Cushing's disease and Nelson's syndrome}

We present data on six patients treated for corticotroph adenomas, which are summarised in Table 2. These patients had a severe, ongoing disease. Four patients required ongoing treatment with anti-adrenal agents despite having undergone pituitary surgery, two on more than one occasion, as well as CRT. The remaining two had also undergone pituitary surgery and CRT, but had subsequently also required bilateral adrenalectomy, and then developed aggressive Nelson's syndrome. One of these received GK on two occasions to two distinct areas of disease recurrence as indicated in Table 2. The mean interval between conventional and stereotactic radiotherapy was 6.3 years (range 2-22 years).

\section{Other pituitary tumours}

We have also treated eight patients with NFPAs, all of whom had previously undergone surgery (four on more than one occasion) and CRT (interval mean 15.1 years, range 2-26 years). This patient group had a recurrent disease: with progressive increase in the size of visible tumour on serial imaging. One patient with a prolactinoma was also treated. She had undergone surgery and CRT 11 and 8 years prior to GK, as she had developed severe mania on dopamine agonist therapy. The indication for GK in this patient was the development of a diplopia secondary to a new cavernous sinus recurrence associated with a rise in serum prolactin (PRL) from 722 to $3740 \mathrm{mU} / \mathrm{l}$ (upper limit of normal $380 \mathrm{mU} / \mathrm{l})$. The details of these patients are summarised in Table 2.

\section{Previous radiotherapy}

CRT had been administered at various different centres in the UK and elsewhere. The median dose was $45 \mathrm{~Gy}$ that was given in 25 fractions (range 40-45 Gy, with one radioactive Yttrium implant). The mean interval between CRT and GK radiotherapy was 11.8 years (range $1.5-43$ years).

\section{Follow-up assessments}

A baseline evaluation included formal ophthalmological assessment of visual perimetry and visual acuity, contrast-enhanced MRI of the pituitary and basal endocrine function. In those patients not already documented to be panhypopituitary, dynamic endocrine testing using insulin-induced hypoglycaemia was used to seek deficiencies of the remaining anterior pituitary 
hormones unless basal cortisol level was above $550 \mathrm{nmol} / \mathrm{l}$ at $0900 \mathrm{~h}$, in which case it was deemed unnecessary. A dose of $0.15 \mathrm{U}$ soluble insulin $/ \mathrm{kg}$ was administered intravenously to achieve hypoglycaemia of $<2.2 \mathrm{mmol} / \mathrm{l}$ to seek deficiencies of ACTH or GH. Where hypoglycaemia was inadequate by $45 \mathrm{~min}$, a repeat dose of $0.15 \mathrm{U} / \mathrm{kg}$ insulin was administered. A rise in serum cortisol to above $550 \mathrm{nmol} / \mathrm{l}$ was defined as normal, and a $\mathrm{GH}$ peak above $9 \mathrm{mIU} / \mathrm{l}(\sim 3.3 \mathrm{ng} / \mathrm{ml})$ was taken to exclude severe GH deficiency (17).

All patients were also assessed clinically by a consultant endocrinologist and oncologist, and were discussed at a pituitary neurosurgical multidisciplinary meeting. Formal psychological testing was not available.

Following GK, patients were reviewed similarly every 3 months for the first year, and annually, including dynamic testing where indicated, thereafter. All patients were assessed clinically for the development of any psychological or neurological changes following radiotherapy, and detailed visual field and acuity assessments were conducted annually to seek evidence of damage to the optic apparatus.

Six out of ten patients with somatotroph adenomas were on treatment at the time GK was administered, although biochemical assessments were made off the medical therapy in one of these (patient 6, Table 1). In the five patients who remained on treatment, all assessments have been made on the same treatments before and after GK (Table 1 and filled symbols in Fig. 1).

Patients were assessed using a GH 'day curve' as described previously by taking the mean of five serum GH levels taken throughout the day and a serum IGF1 level (18). This laboratory measures GH in mIU/l. All analyses were performed by these units, which were then converted to $\mathrm{ng} / \mathrm{ml}$ for this report, using a conversion factor of $5 \mathrm{mIU} / \mathrm{l}=1.8 \mathrm{ng} / \mathrm{ml}$.

Patients with corticotroph adenomas and Cushing's syndrome were similarly assessed by estimating the mean serum cortisol levels obtained from five samples taken through a day from 0900 to $1900 \mathrm{~h}$ (19), and those with Nelson's syndrome with a plasma ACTH level taken $120 \mathrm{~min}$ after a hydrocortisone dose (13). The patient with a prolactinoma was assessed using single PRL levels only.

All hormonal measurements were performed in the Department of Clinical Biochemistry, St Bartholomew's Hospital. Serum IGF1, GH and ACTH were measured using a semi-automated analytical platform (Immulite 2500 analyser, Siemens, Worcester, UK). Serum cortisol, PRL and TSH were assayed using a modular fully automated analytical platform (E170 analyser, Roche Diagnostics).

Contrast-enhanced MRI scanning was performed annually on all patients, with serial images reviewed by the same neuroradiologist ( $\mathrm{J} \mathrm{E}$ ).

\section{GK dose planning and administration}

All patients underwent MRI scanning to localise their residual disease prior to GK planning. The targets were mapped by three-dimensional coordinates using both plain radiographs and CT scanning to aid stereotactic localisation to the bony landmarks. GK software was used to calculate the exact target volume (range 0.61$10.4 \mathrm{cc}$, modal volume $1.1 \mathrm{cc}$ ) and conformation, and to determine the optimal number of isocentres required $($ mode $=$ six isocentres, range 4-16). Proximity to radiosensitive structures was also taken into account using a reverse planning process. Tumours lying within $3 \mathrm{~mm}$ of the optic chiasm were deemed unsuitable for GK, and for all others, the total dose administered was determined by that which will expose the optic chiasm to a maximum of $8 \mathrm{~Gy}$ in patients with no previous radiotherapy exposure, which was reduced pragmatically to $50 \%$, or $4 \mathrm{~Gy}$ for the previously irradiated patients in this series. The modal marginal dose delivered in this series was $10 \mathrm{~Gy}$, which was delivered to the tumour volumes that were between 84 and $97 \%$ (mean dose \pm s.e.m. 13.2 \pm 2.9 , range 10-20 Gy, modal coverage $93 \%$ target volume), although patients receiving $\mathrm{GK}$ as an alternative to $\mathrm{CRT}$ in this centre received a modal dose of $20 \mathrm{~Gy}$ (data not shown). 'Xknife' software was also used during this time period to determine whether linac-based or GK radiosurgery would be safer in delivering the largest dose to the tumour with the minimum dose to the chiasm $(15,20)$. Due to this conservative planning process, 14 patients were considered unsuitable for GK.

Four milligrams of dexamathasone were administered orally $2 \mathrm{~h}$ before, and six hourly for $36 \mathrm{~h}$ following administration of GK, as in the linear accelerator-based series, with all patients admitted overnight for the observation and detection of early complications (15).

\section{Statistical methods}

Microsoft Excel was used for all statistical calculations. Mean values and ranges are given for the fall in biochemical activity post GK and for follow-up times. Modal and mean values are given for GK doses.

\section{Results}

\section{Acromegaly}

GH data The biochemical data for the patients with somatotroph adenomas are summarised in Figs 1 and 2. The full data for disease activity at the time of diagnosis and at CRT administration are not available. Published reports estimate a $50 \%$ fall in $\mathrm{GH}$ within the first 2 years of CRT (14), and this cohort had a mean interval of 13 years between CRT and GK delivery. Patients were thus generally deemed to be within the plateau phase of CRT before GK was considered. In the four patients in whom 


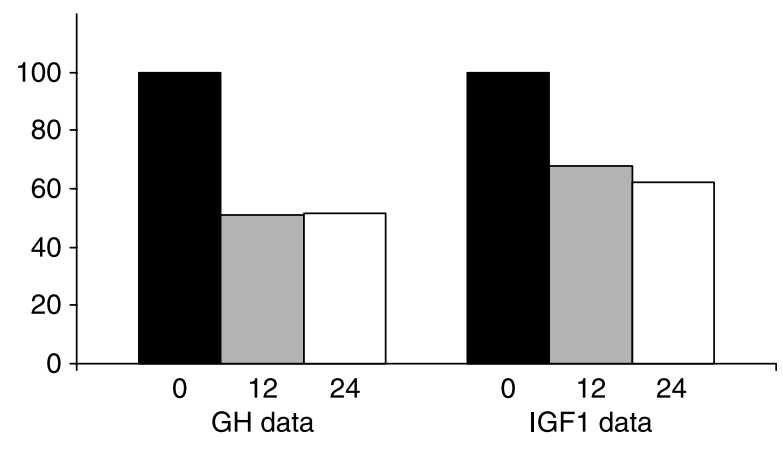

Figure 2 Histogram illustrating the mean serum GH value (left) and mean IGF1 (right) before and at 12 and 24 months post gamma knife, expressed as a percentage of mean $\mathrm{GH}$ that was presented for patients.

full data are available, mean GH had fallen by $62 \%$ over a mean of 17 years following CRT and prior to receiving GK: from 38 to $13 \mathrm{mIU} / \mathrm{l}$. Mean serum GH fell by a further $49 \%$ within 12 months of GK (Figs 1a and 2).

However, selected patients were treated before this plateau phase had been reached. For example, patient 10 listed in Table 1 had received surgery and radiotherapy just 18 months prior to GK. She showed no response to somatostatin analogues or cabergoline, and only partially responded to pegvisomant: with an IGF1 still twice the upper limit of normal. However, within 6 months of GK her IGF1 had normalised on the same dose of pegvisamont, and it is anticipated that this treatment can be reduced and stopped as the effects of radiotherapy and radiosurgery continue.

To date, $43 \%$ (three out of seven patients) have achieved satisfactory control - mean GH levels $<1.8 \mathrm{ng} / \mathrm{ml}$, two of whom are now off all treatments. The third remains on low-dose somatostatin analogue therapy to control the symptoms of headache. Three patients remain on the $\mathrm{GH}$ receptor antagonist pegvisomant, on which it is not possible to interpret GH levels: IGF1 is used as the sole biochemical marker of their disease (Fig. 1b, excluded Fig. 1a).

The radiosurgical dose used did not correlate with the fall in disease activity in this series: patients treated with 10 Gy demonstrated a $61 \%$ fall in mean GH and in IGF1 compared to a $51 \%$ fall in $\mathrm{GH}$ and $37 \%$ fall in IGF1 in those treated with 15-17.5 Gy, with no significant difference between each pair of data.

IGF1 data IGF1 fell by a mean of $32 \%$ at 12 months, $38 \%$ at 24 months and $44 \%$ to the latest follow-up post GK (Figs $1 \mathrm{~b}$ and 2). IGF1 levels fell to within the ageand gender-related reference range in 50\% within 12 months, but by the latest follow-up, $80 \%$ had normalised, with five patients now off all treatments (mean follow-up 38.5 months, mode 36 months, range 6-78 months) (Fig. 1b). A 19\% increase in IGF1 was observed in one patient; however, he exhibited a fall in $\mathrm{GH}$ level over the same time period.
Satisfactory control was achieved in three out of ten patients as evidenced by both a normal age- and genderrelated serum IGF1 level and a mean $\mathrm{GH}<1.8 \mathrm{ng} / \mathrm{ml}$ (one off all the medical treatments), with a further five out of ten patients achieving a satisfactory serum IGF1 on treatment for the first time (Fig. 1).

Imaging There has been no interval change documented in any of these patients.

Pituitary function Five out of ten patients with acromegaly were panhypopituitary prior to receiving GK: two out of five sustained a partial loss of pituitary function following GK, one remained partially hypopituitary and two remained eupituitary following GK (mean follow-up of these five patients was 31.4 months, range 6-55 months).

Cushing's disease and Nelson's syndrome The clinical details of all patients with corticotroph adenomas are listed in Table 2. One of the two patients with Nelson's syndrome was treated with $10 \mathrm{~Gy}$, and showed excellent long-term control: a $61 \%$ fall in plasma ACTH and disease stabilisation on MRI (follow-up 5 years). The other had very aggressive disease invading the clivus, skull base and subsequently extracranial soft tissues. She received 20 Gy GK on two occasions to two distinct areas of disease (patient 15, Table 2). She showed a temporary response for 12 and 18 months respectively, though she subsequently progressed and has recently received temozolomide chemotherapy (21). Out of the four patients with Cushing's disease, one showed an improvement in cortisol excess - mean cortisol fell by $37 \%$ - and stable disease on imaging to date (12 months). A second patient showed a promising early response with an initial fall in mean cortisol of $88 \%$, but relapsed within 12 months. Two patients showed no response, requiring bilateral adrenalectomy at 9 and 10 months. Again, no direct relationship between radiosurgical dose and clinical response was apparent in this small group. Five out of six patients were panhypopituitary prior to GK, with one remaining eupituitary at 36 months of follow-up. No other adverse events were detected.

\section{Prolactinoma}

This 75-year-old patient showed a 75\% reduction in her PRL level from 3740 to $790 \mathrm{mU} / \mathrm{l}$, with a $30 \%$ volume reduction on MRI scanning at 24 months. She was panhypopituitary before receiving GK and developed no other adverse events (follow-up 42 months).

\section{Non-functioning pituitary adenomas}

All patients with NFPAs underwent GK due to regrowth of previously stable visible disease. Six of eight patients have responded. Two showed a reduction in tumour size 
on serial imaging, and had received 8 and 14 Gy. Four showed disease stabilisation and had received between 10 and $20 \mathrm{~Gy}$ (mean follow-up 44.6 months, range 12-96 months). The remaining two patients showed tumour control for 36 and 66 months but with subsequent re-growth requiring further surgery (Table 2). These two had received comparatively low radiosurgical doses of 9 and $12.5 \mathrm{~Gy}$. It is possible but not proven that higher radiosurgical doses may achieve a better long-term control. Seven out of the eight patients were panhypopituitary prior to receiving GK, with one losing further anterior pituitary function following GK; no other adverse events were detected.

\section{Adverse events}

The treatment was well tolerated by all subjects, with none reporting headache or other immediate complications. The group is small and follow-up is ongoing; however, no new tumours have been detected in the radiotherapy field on serial imaging, and no neurological, cerebrovascular or psychological disturbance has been detected on detailed clinical review of all subjects to date (median follow-up 36 months, range 6-96 months). No new visual field or acuity losses have been detected to date. Out of 25 patients, 18 were panhypopituitary prior to GK, while 3 out of the remaining 7 patients $(43 \%)$ developed partial anterior hypopituitarism following GK. Three patients remain eupituitary, and one with partial hypopituitarism developed no further loss post GK.

Four patients complained of headache prior to GK, of which one improved following GK. Four patients with cavernous sinus disease also complained of diplopia prior to GK. Two with cavernous sinus syndrome experienced complete resolution of their diplopia at 2 and 18 months post GK. The others with isolated III and IV nerve palsies had no change in their symptoms.

\section{Discussion}

This is the first report of the use of GK radiosurgery exclusively in patients who had previously undergone CRT. These data confirm that GK radiosurgery is effective in acromegaly. These data also suggest an improved control in patients with recurrent NFPAs, although a true increase in actuarial progression-free survival or local disease control cannot be confirmed in such a limited number of patients with limited followup. GK was demonstrated to be well tolerated with an excellent safety profile although the follow-up period remains short. Our recorded instance of $43 \%$ new pituitary failure is higher than that observed in the series using GK as a treatment in non-irradiated pituitaries, but it is compatible with other series of repeat pituitary radiotherapies (6), with the majority of such heavily pre-treated patients already being panhypopituitary. We have observed no other significant adverse events to date.

\section{Acromegaly}

The largest patient group treated with GK in the current series had a diagnosis of acromegaly. Controversy exists as to the definition of 'cure' in acromegaly. Most recent consensus statements suggest that attempts should be made to achieve both a normal age- and gender-related IGF1 and a nadir GH below $0.4 \mathrm{ng} / \mathrm{ml}$ following an oral glucose tolerance test $(22,23)$. However, in this group of patients with ongoing biochemical disease and macroadenomas, cure rates are invariably low. In such a population, already on medical therapy, or intolerant of it, and with previous exposure to CRT, we consider any further reduction in disease activity and sparing of the need for expensive or poorly tolerated medical treatments to be worthwhile aims. We have therefore assessed disease activity by comparing the mean of serial serum GH levels before and after treatment, and have taken the percentage fall in activity to be the primary outcome of treatment. Normal survival is associated with the reduction in mean serum GH levels below $5 \mathrm{mIU} / \mathrm{l}$ (which converts to $<1.8 \mathrm{ng} / \mathrm{ml}$ ) and a normalisation of the age- and gender- related serum IGF1 level, and so we have taken this to be a satisfactory disease control, though this was not always possible to achieve in this series $(24,25)$. Furthermore, although all patients were deemed to be stable before considering GK, inevitably some would have been within the phase of slow decline observed following CRT as discussed above. We propose that GK accelerated the fall in biochemical activity in these highly active and poorly controlled tumours allowing biochemical control to be achieved much earlier than otherwise predicted. Controversy also exists as to the possible radioprotective effect of somatostatin analogue treatments $(10,26)$. It was not possible to stop all the medical treatments prior to GK in this series, and the numbers are too small to draw any conclusions on this point. Those patients on treatment are indicated in Table 1 (six out of ten patients).

By analysing this group according to the biochemistry that was presented, it was found that $100 \%$ of the patients presenting with IGF1 less than twice the upper limit of their normal age- and gender-related reference range achieved normal levels, 50\% within the first year. A total of $75 \%$ patients presenting $\mathrm{GH}$ levels less than twice the upper limit of normal $(<3.6 \mathrm{ng} / \mathrm{ml})$ also achieved a satisfactory disease control within 12 months of GK. These data strongly support the use of GK for a biochemically mild disease, and are in keeping with previous reports that the best predictor of GK effectiveness is the initial tumour activity (1, 24-28). This is also in line with other series of surgeries, CRT and medical treatments, all of which show optimal 
outcomes in patients with a biochemically mild disease, usually corresponding to small tumour size on imaging $(29,30)$.

Examining the responses in terms of percentage fall, we report a $49 \%$ fall in $\mathrm{GH}$ and a $32 \%$ fall in serum IGF1 at 1 year. This fall is in addition to the previously observed fall following CRT, and this is expected to continue with continued follow-up. In our unit, mean $\mathrm{GH}$ is predicted to fall by $\sim 50 \%$ at 2 years, and in this series there had been a $62 \%$ fall in $\mathrm{GH}$ since CRT in patients for whom data were available. In these four patients, modal interval between CRT and GK was 13.3 years, (range 1.5-43 years in the complete group) (14). There are very few reports of such refractory acromegaly with which to compare these data.

\section{Other pituitary tumours}

This series also includes 15 patients with nonsomatotroph pituitary adenomas, which were also heavily pre-treated.

A previous report of 100 patients with NFPAs treated with GK reported tumour stabilisation or shrinkage in $92 \%$, with $25 \%$ anterior pituitary failure and no other side effects (31). These data are comparable to standard radiotherapy or linear accelerator-based radiosurgery given in the early post-operative period: 95-100\% local control rate at 10 years compared to $6-46 \%$ control rate at 10 years with no post-operative irradiation (32-34). Our data indicate that GK can also be safely used in the $5 \%$ of the patients who escape control post surgery and CRT. An alternative option for these tumours is to consider a repeat course of standard radiotherapy. In one series, reirradiation of $42 \mathrm{~Gy}$ was delivered to similarly aggressive and recurrent tumours at a median of 10 years after a median initial dose of 41 Gy (6). Overall, control was good considering the nature of this group of patients: $50 \%$ improvement and $50 \%$ stabilisation of visual loss, with local disease control in 12 out of 15 cases. In that series, temporal lobe injury was observed in 2 out of 15 patients, disease progression occurred in 3 out of 15 and all patients who were not already panhypopituitary subsequently became so. A recent review also highlights the unpredictable natural history of NFPAs, and stresses that treatment should be considered for those with visual field deficits and large or growing remnants post surgery only (34). We would therefore advocate that repeat surgery is the safest first-line treatment in NFPA escaping control despite initial conventional surgery and radiotherapy. Where this is not feasible, GK or CRT should be considered on an individual case basis.

Several groups have reported success with GK in Cushing's disease. GK has been used as an alternative to CRT following non-curative surgery, with an early remission rate of $63 \%$ in one series (35). GK and linear accelerator-based radiosurgery have also been used as the primary treatments with good results:
$42-49 \%$ remission rates which are similar to that of neurosurgery alone (36). In this context, our observed response to GK radiosurgery as a salvage treatment is disappointing. GK treatment was, however, well tolerated, with an excellent safety profile, and it provided at least a modest short-term response in four out of six patients, making it an option worth considering in patients with a very severe disease in whom there is currently little else to offer. Other groups have reported success with GK as an alternative to CRT in prolactinomas (37), though there are no previous reports of its use in previously irradiated patients to our knowledge.

\section{Adverse events}

There are multiple reports of complications such as cognitive problems, visual loss, second brain tumours and cerebrovascular disease following pituitary radiotherapy $(29,30,38,39)$. It has been suggested that the rates of anterior pituitary failure and other complications may be lower following pituitary radiosurgery than those following CRT due to the ability to closely map radiation exposure to the target rather than to the pituitary fossa as a whole $(8,40)$. The patients in this series are not comparable to those in other published GK series due to their previous exposure to CRT, and the relatively low radiosurgical doses used (mode $10 \mathrm{~Gy}$ ). However, in this context, the safety profile is notable, although the median follow-up remains short: 36 months.

Finally, while safety concerns remain about the repeat application of CRT $(6,7)$, and there are no published reports of CRT following radiosurgery to date, this represents the second series demonstrating the safety and efficacy of radiosurgery following CRT, with no significant adverse effects being detected to date (15).

\section{Conclusions}

In summary, we demonstrate that in severe pituitary disease that is resistant to conventional treatments, including radiotherapy and previous surgery, GK represents a safe salvage treatment. In this series, GK led to an accelerated fall in $\mathrm{GH}$ excess and stabilisation of NFPAs in the majority of cases.

\section{Declaration of interest}

There is no conflict of interest that could be perceived as prejudicing the impartiality of the research reported.

\section{Funding}

This research did not receive any specific grant from any funding agency in the public, commercial or not-for-profit sector. 


\section{Acknowledgements}

The authors wish to thank the following referring clinicians who kindly allowed their patients to be included in this work: Dr James Ahlquist, Dr Gerard Conway, Dr Stephanie Baldeweg and Prof. Peter Trainer and Dr Jane Evanson for reviewing all the pituitary imaging.

\section{References}

1 Prevedello DM, Pouratian N, Sherman J, Jane JA Jr, Vance ML, Lopes MB \& Laws ER Jr. Management of Cushing's disease: outcome in patients with microadenoma detected on pituitary magnetic resonance imaging. Journal of Neurosurgery $2008 \mathbf{1 0 9}$ 751-759.

2 Castinetti F, Morange I, Dubois N, Albarel F, Conte-Devolx B, Dufour $\mathrm{H} \&$ Brue T. Does first-line surgery still have its place in the treatment of acromegaly? Annales d'Endocrinologie $2009 \mathbf{7 0}$ $107-112$.

3 Gittoes NJ, Bates AS, Tse W, Bullivant B, Sheppard MC, Clayton RN \& Stewart PM. Radiotherapy for non-functioning pituitary tumours. Clinical Endocrinology 199848 331-337.

4 Brada M \& Jankowska P. Radiotherapy for pituitary adenomas. Endocrinology and Metabolism Clinics of North America 200837 263-275.

5 Trainer PJ, Drake WM, Katznelson L, Freda PU, Herman-Bonert V, van der Lely AJ, Dimaraki EV, Stewart PM, Friend KE, Vance ML, Besser GM, Scarlett JA, Thorner MO, Parkinson C, Klibanski A, Powell JS, Barkan AL, Sheppard MC, Malsonado M, Rose DR, Clemmons DR, Johannsson G, Bengtsson BA, Stavrou S, Kleinberg DL, Cook DM, Phillips LS, Bidlingmaier M, Strasburger CJ, Hackett S, Zib K, Bennett WF \& Davis RJ. Treatment of acromegaly with the growth hormone-receptor antagonist pegvisomant. New England Journal of Medicine 2000 342 1171-1177.

6 Schoenthaler R, Albright NW, Wara WM, Philips TL, Wilson CB \& Larson DA. Reirradiation of pituitary adenoma. International Journal of Radiation Oncology, Biology, Physics 199224 307-314.

7 Flickinger JC, Deutsch M \& Lunsford LD. Repeat megavoltage irradiation of pituitary and suprasellar tumours. International Journal of Radiation Oncology, Biology, Physics 198917 171-175.

8 Prasad D. Clinical results of conformal radiotherapy and radiosurgery for pituitary adenoma. Neurosurgery Clinics of North America 200617 129-141.

9 Kong DS, Lee JI, Lim do H, Kim KW, Shin HJ, Nam DH, Park K \& Kim JH. The efficacy of fractionated radiotherapy and stereotactic radiosurgery for pituitary adenomas: long-term results of 125 consecutive patients treated in a single institution. Cancer 2007 110 854-860.

10 Losa M, Gioia L, Picozzi P, Franzin A, Valle M, Giovanelli M \& Mortini $\mathrm{P}$. The role of stereotactic radiotherapy in patients with growth hormone-secreting pituitary adenoma. Journal of Clinical Endocrinology and Metabolism 200893 2546-2552.

11 Pollock BE, Cochran J, Natt N, Brown PD, Erickson D, Link MJ, Garces YI, Foote RL, Stafford SL \& Schomberg PJ. Gamma knife radiosurgery for patients with non-functioning pituitary adenomas: results from a 15-year experience. International Journal of Radiation Oncology, Biology, Physics 200870 1325-1329.

12 Tsagarakis S, Grossman AB \& Plowman PN. Megavoltage radiotherapy in the management of prolactinomas: long term follow-up. Clinical Endocrinology 199134 399-406.

13 Jenkins PJ, Trainer PJ, Plowman PN, Shand WS, Grossman AB, Wass JA \& Besser GM. The long-term outcome after adrenalectomy and prophylactic pituitary radiotherapy in adrenocorticotropindependent Cushing's syndrome. Journal of Clinical Endocrinology and Metabolism $1995 \mathbf{8 0} 165-171$.

14 Plowman PN. Pituitary adenoma radiotherapy - when, who and how? Clinical Endocrinology 199951 265-271.

15 Swords FM, Allan CA, Plowman PN, Sibtain A, Evanson J, Chew SL, Grossman AB, Besser GM \& Monson JP. Stereotactic radiosurgery XVI: a treatment for previously irradiated pituitary adenomas. Journal of Clinical Endocrinology and Metabolism 2003 88 5334-5340.

16 Edwards AE, Swords FM \& Plowman PN. Focal radiation therapy for patients with persistent/recurrent pituitary adenoma, despite previous radiotherapy. Pituitary 200912 30-34.

17 Hoffman DM, O'Sullivan AJ, Baxter RC \& Ho KK. Diagnosis of growth hormone deficiency in adults. Lancet $1994 \mathbf{3 4 3}$ 1064-1068.

18 Kaltsas GA, Isidori AM, Florakis D, Trainer PJ, CamachoHubner C, Afshar F, Sabin I, Jenkins PJ, Chew SL, Monson JP, Besser GM \& Grossman AB. Predictors of the outcome of surgical treatment in acromegaly and the value of the mean growth hormone day curve in assessing post operative disease activity. Journal of Clinical Endocrinology and Metabolism 200186 1645-1652.

19 Trainer PJ, Easiment C, Grossman AB, Wheeler MJ, Perry L \& Besser GM. The relationship between cortisol production rate and serial cortisol estimation in patients on medical therapy for Cushing's syndrome. Clinical Endocrinology 199339 441-443.

20 Plowman PN \& Doughty D. Stereotactic radiosurgery, X: clinical isodosimetry of gamma knife versus linear accelerator X-knife for pituitary and acoustic tumours. Clinical Oncology 199911 321-329.

21 Moyes VJ, Alusi G, Sabin HI, Evanson J, Berney DM, Kovacs K, Monson JP, Plowman PN \& Drake WM. Treatment of Nelson's syndrome with temozolomide. European Journal of Endocrinology $2009160115-119$.

22 Melmed S, Casanueva F, Cavagnini F, Chanson P, Frohman LA, Gaillard R, Ghigo E, Ho K, Jaquet P, Kleinberg D, Lamberts S, Laws E, Lombardi G, Sheppard MC, Thorner M, Vance ML, Wass JA \& Giustina A. Consensus statement: medical management of acromegaly. European Journal of Endocrinology 2005153 $737-740$.

23 Guistina A, Barkan A, Casannueva FF, Cavagnini F, Frohman L \& Ho K. Criteria for cure of acromegaly: a consensus statement. Journal of Clinical Endocrinology and Metabolism $2000 \mathbf{8 5}$ $526-529$.

24 Swearingham B, Barker FG, Katznelson L, Biller BL, Grinspoon S \& Klibanski A. Long term mortality after trans-sphenoidal surgery and adjunctive therapy for acromegaly. Journal of Clinical Endocrinology and Metabolism 199883 3419-3426.

25 Jenkins PJ, Bates P, Carson MN, Stewart PM \& Wass JA. Conventional pituitary irradiation is effective in lowering serum growth hormone and insulin-like growth factor-I in patients with acromegaly. Journal of Clinical Endocrinology and Metabolism 2006 91 1239-1245.

26 Pollock BE, Jacob JT, Brown PD \& Nippoldt TB. Radiosurgery of growth hormone-producing pituitary adenomas: factors associated with biochemical remission. Journal of Neurosurgery 20076 833-838.

27 Castinetti F, Taieb D, Kuhn JM, Chanson P, Tamura M, Jacquet P, Conte-Devolx B, Regis J, Dufour H \& Brue T. Outcome of gamma knife radiosurgery in 82 patients with acromegaly: correlation with initial hypersecretion. Journal of Clinical Endocrinology and Metabolism 200590 4483-4488.

28 Jezkova J, Marek J, Hana V, Krsek M, Weiss V, Vladya V, Lisak R, Vymazal J \& Pecen L. Gamma knife radiosurgery for acromegaly long term experience. Clinical Endocrinology 200665 588-595.

29 Laws ER. Surgery for acromegaly: evolution of the techniques and outcomes. Journal of Clinical Endocrinology and Metabolism 2008 $932957-2968$.

30 Minniti G, Traish D, Ashley S, Gonsalves A \& Brada M. Risk of second barin tumour after conservative surgery and radiotherapy for pituitary adenoma: update after an additional 10 years. Journal of Clinical Endocrinology and Metabolism 200590 800-804.

31 Mingione V, Yen CP, Vance ML, Steiner M, Sheehan JP, Laws ER \& Steiner L. Gamma surgery in the treatment of non-secretory pituitary macroadenoma. Journal of Neurosurgery $2006 \mathbf{1 0 4}$ 876-883. 
32 van den Bergh CH, van den Berg G, Schoorl MA, Sluiter WJ, van den Vleit AM, Hoving EW, Szabo BG, Langendijk JA, Wolffenbuttel BH \& Dullart RP. Immediate postoperative radiotherapy in residual non-functioning pituitary adenoma: beneficial effect on local control without additional negative impact on pituitary function and life expectancy. International Journal of Radiation Oncology, Biology. Physics 200667 863-869.

33 Selch MT, Gorgulho A, Lee SP, Mattozo C, Solberg TD, Agasaryan N \& Desalles AA. Stereotactic radiotherapy for the treatment of pituitary adenomas. Minimally Invasive Neurosurgery 200649 150-155.

34 Dekkers OM, Pereira AM \& Romijn JA. Treatment and follow-up of clinically nonfunctioning pituitary macroadenomas. Journal of Clinical Endocrinology and Metabolism 200893 3717-3726.

35 Sheehan JM, Vance ML, Sheehan JP, Ellagala DB \& Laws ER. Radiosurgery for Cushing's disease after failed trans-sphenoidal surgery. Journal of Neurosurgery 200093 738-742.

36 Castinetti F, Nagai M, Dufour H, Kuhn JM, Morange I, Jacquet P, Conte-Devolx B, Regis J \& Brue T. Gamma knife radiosurgery is a successful adjunctive treatment in Cushing's disease. European Journal of Endocrinology 2007156 91-98.
37 Pouratian N, Sheehan JM, Jagannathen J, Laws ER, Steiner L \& Vance ML. Gamma knife radiosurgery for medically and surgically refractory prolactinomas. Neurosurgery 200659 255-266.

38 Gnanalingham KK, Chakraborty A, Galloway M, Revesz T \& Powell M. Osteosarcoma and fibrosarcoma caused by postoperative radiotherapy for a pituitary adenoma. A case report. Journal of Neurosurgery 200296 960-963.

39 Mackley HB, Reddy CA, Lee SY, Harnisch GA, Mayberg MR, Hamrahian AH \& Suh JH. Intensity modulated radiotherapy for pituitary adenomas: the preliminary report of the Cleveland clinic experience. International Journal of Radiation Oncology, Biology, Physics 200767 232-239.

40 Schindler K, Christ ER, Minderman T \& Wieser HG. Transient MR changes and symptomatic epilepsy following gamma knife treatment of a residual GH secreting pituitary adenoma in the cavernous sinus. Acta Neurochirurgica 2006148 903-908.

Received 17 August 2009

Accepted 25 August 2009 